\title{
Oxygen uptake by aquatic sediments measured with a novel non-invasive eddy-correlation technique
}

 \\ Markus Huettel ${ }^{2,3}$, Dirk de Beer ${ }^{2}$ \\ ${ }^{1}$ Department of Environmental Sciences, University of Virginia, 291 McCormick Road, Charlottesville, \\ Virginia 22904-4123, USA \\ ${ }^{2}$ Max Planck Institute for Marine Microbiology, Celsiusstrasse 1, 28359 Bremen, Germany \\ ${ }^{3}$ Present address: Department of Oceanography, Florida State University, 0517OSB, West Call Street, Tallahassee, \\ Florida 32306-4320, USA
}

\begin{abstract}
This paper presents a new non-invasive technique for measuring sediment $\mathrm{O}_{2}$ uptake that, in its concept, differs fundamentally from other methods used to date. In almost all natural aquatic environments, the vertical transport of $\mathrm{O}_{2}$ through the water column toward the sediment surface is facilitated by turbulent motion. The new technique relies on measuring 2 parameters simultaneously and at the same point in the water above the sediment: the fluctuating vertical velocity using an acoustic Doppler velocimeter and the fluctuating $\mathrm{O}_{2}$ concentration using an $\mathrm{O}_{2}$ microelectrode. From these 2 parameters, which typically are measured 10 to $50 \mathrm{~cm}$ above the sediment surface for a period of 10 to $20 \mathrm{~min}$ and at a frequency of 15 to $25 \mathrm{~Hz}$, the vertical flux of $\mathrm{O}_{2}$ toward the sediment surface is derived. Based on measurements performed under actual field conditions and comparisons with in situ flux-chamber measurements, we believe that this new technique is the optimal approach for determining $\mathrm{O}_{2}$ uptake by sediments. The technique is superior to conventional methods as measurements are done under true in situ conditions, i.e. without any disturbance of the sediment and under the natural hydrodynamic conditions. Furthermore, this technique can be used for bio-irrigated or highly permeable sediments, such as sands, where traditional methods often fail. While this paper only focuses on $\mathrm{O}_{2}$ uptake by sediments, the technique can also be applied to other solutes that can be measured at a sufficiently high temporal resolution.
\end{abstract}

KEY WORDS: Oxygen uptake $\cdot$ Sediment $\cdot$ Eddy-correlation measurements

\section{INTRODUCTION}

Background. Consumption of $\mathrm{O}_{2}$ in aquatic sediments is attributed to 3 types of processes: aerobic decomposition of organic matter, animal respiration and oxidation of reduced products of anaerobic decay, including $\mathrm{NH}_{4}{ }^{+}, \mathrm{Mn}^{2+}, \mathrm{Fe}^{2+}, \mathrm{H}_{2} \mathrm{~S}, \mathrm{FeS}$, and $\mathrm{FeS}_{2}$. Sediment $\mathrm{O}_{2}$ uptake provides valuable information on these processes and is a frequently measured parameter in studies of aquatic sediments. At the same time, it is a parameter that is often difficult to measure accurately with the methods available to date.
Oxygen uptake by sediments is affected strongly by the transport processes responsible for the movement of $\mathrm{O}_{2}$ from the overlying water down through the sediment. These transport processes include molecular diffusion, bioturbation (the diffusion-like transport of solutes and solids caused by movements of fauna), bioirrigation (the transport of solutes caused by pumping activity of tube-dwelling animals), and current- or wave-driven advection. Recent studies have shown that bioturbation is often a significant transport process, comparable in strength to molecular diffusion (Aller \& Aller 1992, Forster et al. 1995, Berg et al. 2001). Likewise, bio-irrigation can be a dominant 
transport process in sediments densely populated by tube-dwelling animals (Aller 1983, Pelegri et al. 1994, Wang \& Van Cappellen 1996). Other transport processes can also stimulate $\mathrm{O}_{2}$ uptake by sediments. Currents over an uneven bottom or wave action at shallow sites can induce a significant advective transport, either through the interstitial pores in more permeable sediments such as sand, or through tubes and borrows created by fauna (Rutgers van der Loeff 1981, Savant et al. 1987, Thibodeaux \& Boyle 1987, Huettel \& Gust 1992, Shum 1992, Webster 1992, Webster \& Taylor 1992). This advection can be the dominant transport process in sediments, and enhances $\mathrm{O}_{2}$ uptake manyfold relative to uptake by molecular diffusion (Malan \& McLachlan 1991, Forster et al. 1996, Lohse et al. 1996).

The 2 commonly used methods for determining $\mathrm{O}_{2}$ uptake by sediments are measurements in recovered sediment cores kept in a controlled environment as close to the in situ conditions as possible (e.g. Mortimer 1941, Hayes \& MacAulay 1959, Rasmussen \& Jørgensen 1992), and measurements in in situ chambers which isolate a fraction of the sediment surface and bottom water from the surroundings (e.g. Odum 1957, Pamatmat \& Fenton 1968, Jahnke \& Christiansen 1989). In both cases, the sediment $\mathrm{O}_{2}$ uptake is determined by measuring $\mathrm{O}_{2}$ depletion in the overlying water over time. Typically, sediment cores have a diameter of 5 to $10 \mathrm{~cm}$, while chambers cover a larger area of the sediment surface, for example $30 \times 30 \mathrm{~cm}$ (Glud et al. 1998, 1999).

One problem with these methods is that they may affect active transport processes that influence $\mathrm{O}_{2}$ uptake in the undisturbed sediment. While a good representation of in situ molecular diffusion and also in situ bioturbation caused by smaller animals (meiofauna) can be obtained in sediment cores, this method tends to underestimate the effects of bioturbation and bio-irrigation caused by larger animals (macrofauna). Several studies comparing $\mathrm{O}_{2}$ uptake measured in cores and in situ chambers for the same sediment have found $\mathrm{O}_{2}$ uptake to be several-fold lower in cores (Glud et al. 1998, 1999, 2003). The difference was explained in these comparisons as a result of a more realistic representation of irrigating macrofauna in the larger chambers. In addition, when measurements are made in both sediment cores and in situ chambers, the overlying water is kept fully mixed by stirring. This induced rotational flow differs from naturally occurring flow patterns over the sediment surface and represents another problem of these conventional methods. Furthermore, representative $\mathrm{O}_{2}$ uptake generally can not be measured in cores or in in situ chambers, where advective transport processes within a highly permeable sediment are created by current or wave action (Huettel \& Webster 2001, Reimers et al. 2001). In addition to these shortcomings, measurements in sediment core and in situ chambers are difficult to perform when objects such as rocks, mussels, epifauna, and macroalgae are abundant either on the sediment surface or in the upper sediment layer. Under such circumstances, it is difficult not to disturb the sediment considerably when cores are collected or when in situ chambers are deployed.

This paper presents a new non-invasive technique for measuring $\mathrm{O}_{2}$ uptake by aquatic sediments. In almost all natural environments, $\mathrm{O}_{2}$ taken up by sediments is transported down through the water column by turbulent motion. The new technique relies on measuring turbulent fluctuations in the vertical velocity and the corresponding $\mathrm{O}_{2}$ concentration simultaneously and at the same point above the sediment surface. If such measurements are done with an adequate temporal resolution to capture these fluctuations and for a period long enough to obtain a statistically sound representation of their variations, then the vertical flux of $\mathrm{O}_{2}$ can be derived. If possible to perform from a technical point of view, such measurements obviously do not suffer from the same shortcomings as core and in situ chamber measurements because $\mathrm{O}_{2}$ uptake is determined under true in situ conditions, i.e. without any disturbance of the sediment and under the natural hydrodynamic conditions. This technique has been used for several decades to determine land-atmosphere and sea-atmosphere exchanges of $\mathrm{CO}_{2}$, moisture, and energy in the atmospheric boundary layer (e.g. Wyngaard 1989), and is commonly referred to as flux measurement by eddy-correlation. This term is adopted here. Despite the clear advantages of the technique, it has only been used a few times in aquatic environments to determine fluxes of energy, for example between water and sea ice (Fukuchi et al. 1997, Shirasawa et al. 1997). The obvious reason is that, other than for temperature, it is difficult to construct a sensor that can measure scalar properties such as $\mathrm{O}_{2}$ concentration in water at a well-defined point and with a sufficiently fast response to capture all turbulent fluctuations. However, as documented below, we have been able to make these measurements with an $\mathrm{O}_{2}$ microelectrode constructed to have a fast response. The fluctuating vertical velocity is measured using an acoustic Doppler velocimeter (ADV). The ADV gives the full 3D turbulent velocity field and is widely used in aquatic environments to study processes such as the transport of particles in the shear layer over sediment surfaces.

Theory. Fig. 1 shows an example of a vertical profile of the $\mathrm{O}_{2}$ concentration in a marine muddy sediment and the overlying water measured in situ with a microelectrode. The $\mathrm{O}_{2}$ is consumed in the upper $1.5 \mathrm{~mm}$ of the sediment, and the smoothness of the profile suggests that the important mechanisms for the vertical transport of $\mathrm{O}_{2}$ in the sediment are molecular diffusion 


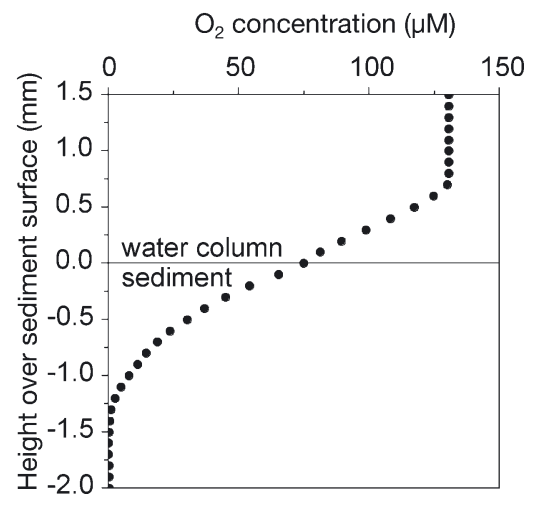

Fig. 1. Vertical profile of $\mathrm{O}_{2}$ concentration measured in situ with a microelectrode in marine muddy sediment and overlying water (Aarhus Bay, Denmark)

and possibly bioturbation caused by meiofauna. In the water column, where the 2 possible transport mechanisms are molecular diffusion and advection, no concentration gradients are visible at $0.7 \mathrm{~mm}$ or higher above the sediment surface. This reflects a shift in the dominant transport process from molecular diffusion within the diffusive boundary layer to advection above the layer. Since there was no continuous advective flow directed toward the sediment at this site, the advective transport of $\mathrm{O}_{2}$ results exclusively from turbulent motions. The typical variation in the $\mathrm{O}_{2}$ concentration and the vertical velocity is that the $\mathrm{O}_{2}$ concentration is slightly higher when the vertical velocity is pointing down toward the sediment and lower when the velocity is pointing upward. Over time, this correlation gives rise to a net transport of $\mathrm{O}_{2}$ toward the sediment. An example of this pattern is shown in Fig. 2, from some of our measurements with high temporal resolution of the vertical velocity and the associated $\mathrm{O}_{2}$ concentration.

The mathematical expression for the vertical $\mathrm{O}_{2}$ flux due to advection and molecular diffusion at any position in the water column at any point in time is

$$
\text { Flux }=u_{z} C-D \frac{\mathrm{d} C}{\mathrm{~d} z}
$$

where $u_{z}$ is the vertical velocity, $C$ is the $\mathrm{O}_{2}$ concentration, $D$ is the molecular diffusivity of $\mathrm{O}_{2}$ in water, and $z$ is the vertical coordinate (e.g. Berner 1980, Boudreau 1997).

Turbulent advection is the dominant vertical transport in the water column above the diffusive boundary layer in almost all natural aquatic environments. For that reason, the diffusive term in Eq. (1) can be neglected. Furthermore, it is common practice when dealing with turbulent motions to separate both instantaneous values of $u_{z}$ and $C$ into 2 components equal to $\bar{u}_{z}+u^{\prime}{ }_{z}$ and $\bar{C}+C^{\prime}$, where $\bar{u}_{z}$ is the mean vertical velocity, $u_{z}^{\prime}$ is the vertical turbulent fluctuating velocity, $\bar{C}$ is the mean concentration, and $C^{\prime}$ is the turbulent fluctuating concentration (e.g. Reynolds 1895, Stanišić 1985, Boudreau 1997). It should be noted that there are no simplifications hidden in these separations. The separations are now substituted into Eq. (1), which is then averaged over a period of time significantly longer than the time scale of the turbulent fluctuations, in which case averages of both $u_{z}^{\prime}$ and $C^{\prime}$ become equal to zero. It is finally assumed that that the mean vertical velocity is equal to zero $\left(\bar{u}_{z}=0\right)$. With these assumptions, Eq. (1) gives the following expression for the vertical $\mathrm{O}_{2}$ flux averaged over time:

$$
\overline{\text { Flux }}=\overline{u^{\prime}{ }_{z} C^{\prime}}
$$

where the bars symbolize the averaging. The derivation of Eq. (2) from Eq. (1), often referred to as the Reynolds' decomposition, is described in more detail in numerous publications (e.g. Reynolds 1895, Stanišić 1985, Boudreau 1997). Eq. (2) has been used for several decades to determine fluxes by eddy-correlation in the atmospheric boundary layer (e.g. Wyngaard 1989). In practical applications of Eq. (2), where a time series of $u_{z}^{\prime}\left(u_{z 1}^{\prime}, u_{z 2}^{\prime}, u_{z 3}^{\prime}, \ldots u_{z N}^{\prime}\right)$ and $C^{\prime}\left(C^{\prime}{ }_{1}, C^{\prime}{ }_{2}, C^{\prime}{ }_{3}, \ldots C^{\prime}{ }_{N}\right)$ is extracted from measurements, the flux is simply calculated as the average of the sum $u_{z 1}^{\prime} C^{\prime}{ }_{1}+u_{z 2}^{\prime} C^{\prime}{ }_{2}+$ $u_{z 3}^{\prime} C_{3}^{\prime}+\ldots+u_{z N}^{\prime} C_{N}^{\prime}$.
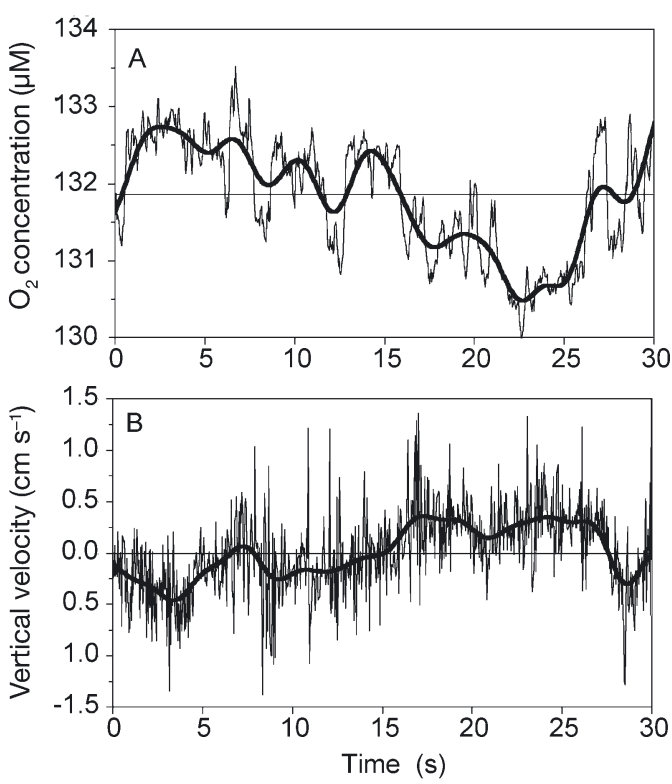

Fig. 2. Time series of (A) fluctuating $\mathrm{O}_{2}$ concentration (thin line) and (B) associated vertical velocity (thin line). Positive velocity values indicate flow up and away from sediment surface. Data were measured $15 \mathrm{~cm}$ above a sediment surface at a frequency of $25 \mathrm{~Hz}$. Mean values for time series are also shown (horizontal lines), as are the smoothed $\mathrm{O}_{2}$ concentration and the smoothed vertical velocity (thick lines) (Aarhus Bay, Denmark) 
When measuring $u_{z}$ in the water column under timeinvariant conditions, i.e. where no changes in size or direction of the current occur, $\bar{u}_{z}$ can be defined as the mean of all measured $u_{z}$. Since it is difficult to position the ADV so that the $u_{z}$ is measured exactly perpendicular to the sediment surface (which in turn may not be completely even and well-defined), $\bar{u}_{z}$ calculated from the measurements is likely to have some small value, and a correction must be made for Eq. (2) to be valid. The correction can be made by rotating the measured $3 \mathrm{D}$ velocity field $\left(u_{x}, u_{y}, u_{z}\right.$, where $u_{x}$ and $u_{y}$ are the 2 horizontal velocity components) so $\bar{u}_{z}$ equals zero. If $\bar{u}_{z}$ is only slightly off zero, the correction can be made simply by subtracting $\bar{u}_{z}$ from each individual $u_{z}$ value. In the latter case, $u_{z}^{\prime}$ becomes equal to $u_{z}-\bar{u}_{z}$ and the average of all $u^{\prime}{ }_{z}$ will consequently always equal zero, as assumed in the derivation of Eq. (2). If time-variant conditions are present, the correction must vary in time, and $u^{\prime}{ }_{z}$ can, for example, be calculated from the running average of $u_{z}$. A challenging aspect of this more advanced correction, as discussed in detail below, is to determine how many adjacent data points to include in the running average. If too few points are included, some of the larger scale turbulent fluctuations are filtered out, and if too many points are included, non-turbulent motions may affect the flux calculation. The isolation of $C^{\prime}$ from the measured $\mathrm{O}_{2}$ concentration $(C)$, is done along the same lines.

Analysis of our measurements have shown that $u_{z}^{\prime}$ can often be calculated as $u_{z}-\bar{u}_{z}$, while $C^{\prime}$ in most situations technically should be calculated from the running average of $C$, since non-turbulent variations in $C$ occur, presumably caused by a slow drift in the $\mathrm{O}_{2}$ microelectrode calibration. However, the running average of $C$ can be avoided if these variations happen on a time scale significantly larger that the scale of the turbulent fluctuations. In such situations $C$ can be used directly in the flux calculation as

$$
\overline{\text { Flux }}=\overline{u_{z}^{\prime} C}
$$

Eq. 3 represents the simplest way to determine sediment $\mathrm{O}_{2}$ uptake from a measured time series of $u_{z}$ and $C$.

If both $u^{\prime}{ }_{z}$ and $C^{\prime}$ are extracted from the measured data, other advantages exist. Both Eqs. (2) and (3) represent an integration in the time domain. This integration can also be performed in the frequency domain after fast Fourier transformation of the time series of $u_{z}^{\prime}$ and $C^{\prime}$. More specifically, the vertical $\mathrm{O}_{2}$ flux can also be expressed as the integral over the frequency of the 1-sided cospectrum of $u_{z}^{\prime} C^{\prime}$ (e.g. Stull 1988, Priestley 1992):

$$
\overline{\text { Flux }}=\int_{0}^{\infty} \mathrm{Co}_{u_{z}^{\prime} c^{\prime}}(f) d f
$$

where $f$ is the frequency. This means that the cospectrum of $u_{z}^{\prime} C^{\prime}$ itself expresses the magnitude of the vertical $\mathrm{O}_{2}$ flux at different frequencies. As shown below, this information can be used to evaluate if the $\mathrm{O}_{2}$ microelectrode responds fast enough to capture all turbulent fluctuations facilitating the vertical transport of $\mathrm{O}_{2}$.

\section{MATERIALS AND METHODS}

Instruments. The ADV is a commercially available instrument manufactured by companies such as Nortek AS and SonTek/YSI. The ADV measures the $3 \mathrm{D}$ velocity in a small cylindrical volume, approximately $1.5 \mathrm{~cm}$ long and $0.6 \mathrm{~cm}$ in diameter, located on the ADV's center line, $10 \mathrm{~cm}$ from the base of the 3 sensors (Fig. 3). Velocities are determined with a frequency as high as $25 \mathrm{~Hz}$. The ADV measurements are largely unaffected by water quality (O'Riordan et al. 1996). However, the speed of sound in water is correlated to temperature and salinity, and these parameters must be known in order to obtain the most accurate determination of the $3 \mathrm{D}$ velocity field.

The $\mathrm{O}_{2}$ microelectrode is of the Clark-type (Revsbech 1989) and, using a thin silicone membrane and a compact tip, is constructed so as to have a short response time. The sensor has a $10 \mu \mathrm{m}$ diameter tip and a 0.2 s response time for a $90 \%$ response to concentration changes. We constructed the electrode our-

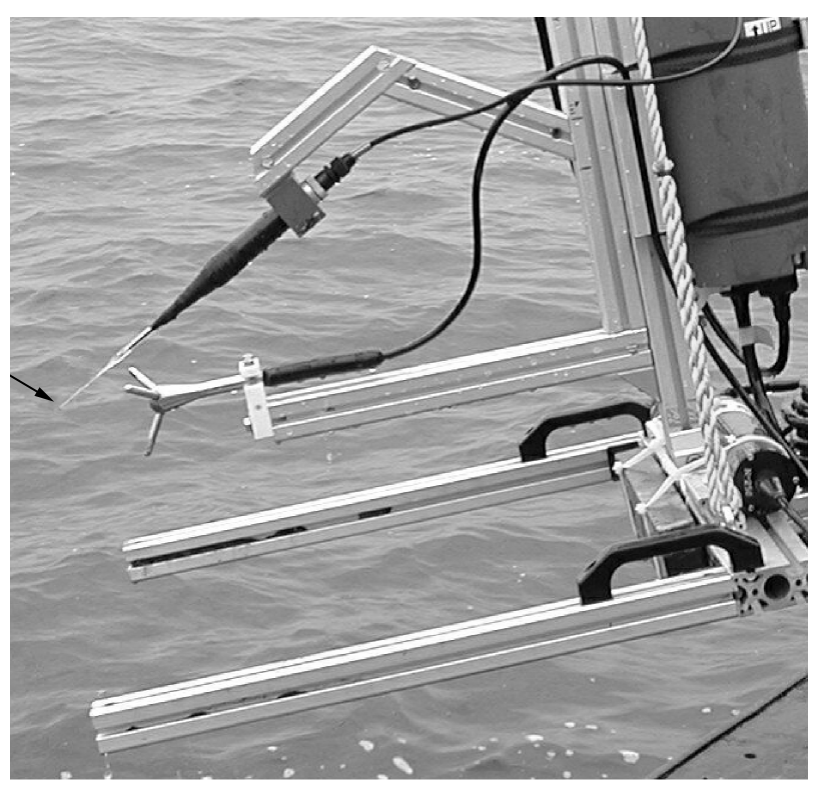

Fig. 3. Acoustic Doppler velocimeter and $\mathrm{O}_{2}$ microelectrode mounted on a rack. Arrow indicates position of acoustic Doppler velocimeter's measuring volume and tip of $\mathrm{O}_{2}$ microelectrode 
selves, but electrodes with similar specifications are produced and sold by companies such as Unisense A/S. The $\mathrm{O}_{2}$ microelectrode was connected to a pico-ampere meter. To maximize signal-to-noise ratio, sensitivity and signal speed, the cable connections between sensor and pico-ampere meter were kept as short as possible. This was achieved by using a customized submersible pico-ampere meter in which the sensor was inserted directly into the amplifier housing (Fig. 3). Since seawater acts as a shield, this picoampere meter can resolve significantly smaller fluctuations in situ than under normal laboratory conditions.

Both the ADV and the $\mathrm{O}_{2}$ microelectrode were mounted on a rack constructed for initial tests of the technique (Fig. 3). The tip of the microelectrode was located immediately next to the border of the ADV's measuring volume. The rack was designed so that the position of the measuring volume and the tip of the microelectrode could be adjusted 10 to $55 \mathrm{~cm}$ above the sediment surface. Prior to measurements, the rack was positioned manually on the sediment surface with the sensors facing into the current, and the ADV and pico-ampere meter were connected to the surface through independent cables. Data acquisition was controlled above the water surface by an IBM-compatible PC. The PC and supporting electronics were powered by batteries and were isolated galvanically from all other electronic devices.

Both the velocity and the $\mathrm{O}_{2}$ concentration measurements contained some high frequency noise (Fig. 2). The noise from the ADV is purely random, can be assumed to follow a Gaussian distribution, and consequently converges to the value zero when averaged over multiple data points without introducing bias (SonTek/YSI 2001). The electronic circuitry and components behind the $\mathrm{O}_{2}$ concentration measurements are all well-known and well-described (e.g. Tietze \& Schenk 2003) and have noise characteristics similar to the ADV. This was confirmed by measurements during which the $\mathrm{O}_{2}$ microelectrode and the ADV were positioned apart. These measurements led to the calculation of an $\mathrm{O}_{2}$ uptake of zero.

Measurements. The technique was tested under field conditions on 3 occasions.

The first series of measurements was done in the River Wümme near Bremen, Germany, which is approximately $7 \mathrm{~m}$ wide, with a water depth of $1 \mathrm{~m}$ and a sandy bottom. This site allowed us to keep all equipment not mounted on the rack on land, and also to make easy adjustments of the orientation of the rack and the measuring height above the sediment surface. Additional measurements for comparison of the $\mathrm{O}_{2}$ uptake in recovered sediment cores or in situ chambers were not made, since these 2 methods are likely to fail in permeable sands, as described above.
At the time of measurement, the river current was 13 $\mathrm{cm} \mathrm{s}^{-1}$. We sampled three $10 \mathrm{~min}$ time series for each of 4 measuring heights: 15, 20, 40 and $55 \mathrm{~cm}$ above the sediment surface. Each time series was sampled at a frequency of $25 \mathrm{~Hz}$ to ensure that all concentration changes that could be registered by the $\mathrm{O}_{2}$ microelectrode were sampled.

The second series of measurements was done in Aarhus Bay, Denmark. The sediment was fine-grained marine mud and was located at $12 \mathrm{~m}$ water depth. At the time of measurement, the current was $2 \mathrm{~cm} \mathrm{~s}^{-1}$ at $15 \mathrm{~cm}$ above the sediment surface. We sampled four $10 \mathrm{~min}$ time series $15 \mathrm{~cm}$ above the sediment surface at a frequency of $25 \mathrm{~Hz}$. For comparison with the eddycorrelation measurements, 4 in situ chambers were deployed. These chambers had an inner diameter of $19 \mathrm{~cm}$ and were $32 \mathrm{~cm}$ in height. The lid on each chamber had a large opening that was closed by a stopper after deployment, a sampling port with syringe holder for water samples, and a second port for replacement of sampled water. The water inside the chambers was stirred during measurements by a flat rotating disk, $15 \mathrm{~cm}$ in diameter and $1 \mathrm{~cm}$ in height. Throughout the $3 \mathrm{~h}$ incubation, the disks were rotated at a speed of $20 \mathrm{rpm}$ in a position approximately $7 \mathrm{~cm}$ above the sediment surface. Prior to measurements, the chambers were pushed approximately $20 \mathrm{~cm}$ into the sediment, enclosing a water volume of approximately $3.2 \mathrm{l}$. A more accurate estimate of this water volume was calculated from the dilution of $50 \mathrm{ml}$ of a neutrally buoyant sodium bromide solution injected into each chamber. Oxygen concentrations in the chambers were monitored during incubation with $\mathrm{O}_{2}$ optrodes (Presens) mounted in the lids. In addition, the $\mathrm{O}_{2}$ concentrations in the chambers were determined by Winkler titration of water samples retrieved at the beginning and the end of the incubation. Oxygen decreased by approximately $20 \%$ in the chambers during the incubation. For additional comparison, 3 vertical profiles of $\mathrm{O}_{2}$ concentration were measured with microelectrodes in sediment cores collected at the site. The deployment of the rack holding the ADV and the $\mathrm{O}_{2}$ microelectrode, the deployment of the in situ chambers and the collection of sediment cores were done by divers.

The third and last series of measurements was carried out in Limfjorden Sound, Denmark. The sediment was a fine-grained marine mud and was located at $8 \mathrm{~m}$ water depth. At the time of measurement, directional changes in the current were observed and its strength varied between 1.5 and $4 \mathrm{~cm} \mathrm{~s}^{-1}$ at $40 \mathrm{~cm}$ above the sediment surface. We sampled six 10 min time series $40 \mathrm{~cm}$ above the sediment surface at a frequency of $25 \mathrm{~Hz}$. For comparison with the eddy-correlation measurements, 6 in situ chambers were deployed and operated as described for the Aarhus Bay site. 




Fig. 4. Mean (+1 SE) $\mathrm{O}_{2}$ uptake by sandy river sediment (River Wümme, Germany) determined by the eddy-correlation technique

\section{RESULTS AND DISCUSSION}

The results of the eddy-correlation measurements in the River Wümme are shown in Fig. 4. The sediment $\mathrm{O}_{2}$ uptake was calculated from Eq. (3), with $u_{z}^{\prime}$ determined as $u_{z}-\bar{u}_{z}$. Some variation in uptake for the different measuring heights was expected, since the rates represent an increasing upstream area of the sediment surface as the measuring heights increased. However, the mean values of the $\mathrm{O}_{2}$ uptake did not differ significantly (ANOVA, p > 0.18), and an overall mean of 210 $\pm 16 \mathrm{mmol} \mathrm{m}^{-2} \mathrm{~d}^{-1}$ was calculated from the combined data. It is expected that some advective transport in the upper sediment layer was induced at a main current of $13 \mathrm{~cm} \mathrm{~s}^{-1}$ during the eddy-correlation measurements, which presumably explains the relatively high $\mathrm{O}_{2}$ uptake. All potential shortcomings and errors in the eddy-correlation measurements, such as the response time of the $\mathrm{O}_{2}$ microelectrode being too long to capture

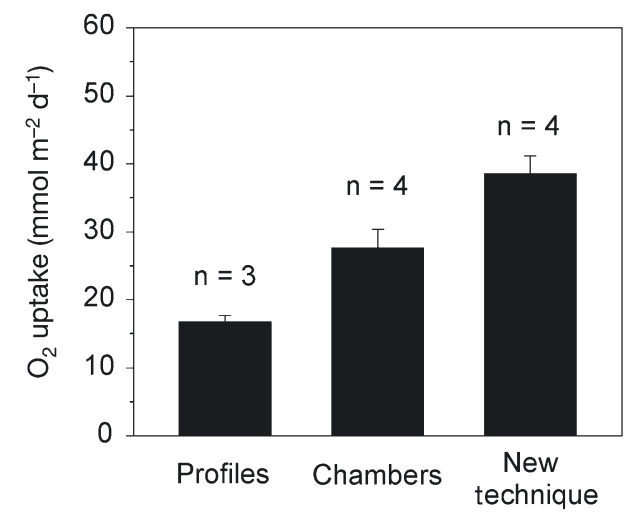

Fig. 5. Mean (+1 SE) $\mathrm{O}_{2}$ uptake by muddy marine sediment (Aarhus Bay, Denmark) determined by $\mathrm{O}_{2}$ micro-profiles, in situ chambers and the new eddy-correlation technique all important turbulent fluctuations, would lead to an underestimation of the $\mathrm{O}_{2}$ uptake. In the light of this, the high uptake, combined with the relatively small error estimates, was viewed as a promising result for the new technique.

Also for the time series from Aarhus Bay, $u_{z}^{\prime}$ was determined as $u_{z}-{ }^{-} u_{z}$ and the sediment $\mathrm{O}_{2}$ uptake was calculated from Eq. (3). The calculated uptake is shown in Fig. 5, as is the result from the in situ chambers and the uptake determined from $\mathrm{O}_{2}$ micro-profiles using the gradients in the diffusive boundary layer. Bio-irrigation is not included in the latter method, which explains the lower estimated $\mathrm{O}_{2}$ uptake relative to the chamber measurements. The $\mathrm{O}_{2}$ uptake determined in chambers and by the new technique differ significantly (ANOVA, p = 0.03), and the difference is probably due to an underrepresentation of faunal activity, especially the irrigating macro-fauna, in the chambers. Since the current was low when the measurements were made, and given the impermeable structure of the muddy sediment, it seems unlikely that advective transport, other than that induced by irrigating fauna, would influence the $\mathrm{O}_{2}$ uptake in the sediment. The relative standard error estimate of $7 \%$ for the $\mathrm{O}_{2}$ uptake determined by eddy-correlation was of the same magnitude as the 10 and $6 \%$ standard errors in the chamber measurements and the flux calculations from micro-profiles, respectively.

As a result of the time-variant current during the measurements in Limfjorden, $u_{z}^{\prime}$ was determined from the running average of $u_{z}$ before the sediment $\mathrm{O}_{2}$ uptake was calculated from Eq. (3). The number of adjacent data points used in the running average was determined in an analysis as detailed below. The calculated $\mathrm{O}_{2}$ uptake is shown in Fig. 6, as is the result from the in situ chambers. The 2 uptake estimates do not differ significantly (ANOVA, $\mathrm{p}=0.50$ ), and have

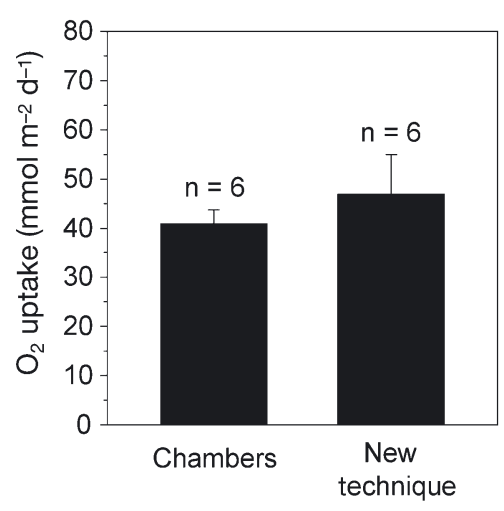

Fig. 6. Mean (+1 SE) $\mathrm{O}_{2}$ uptake by muddy marine sediment (Limfjorden Sound, Denmark) determined by in situ chambers and the new eddy-correlation technique 

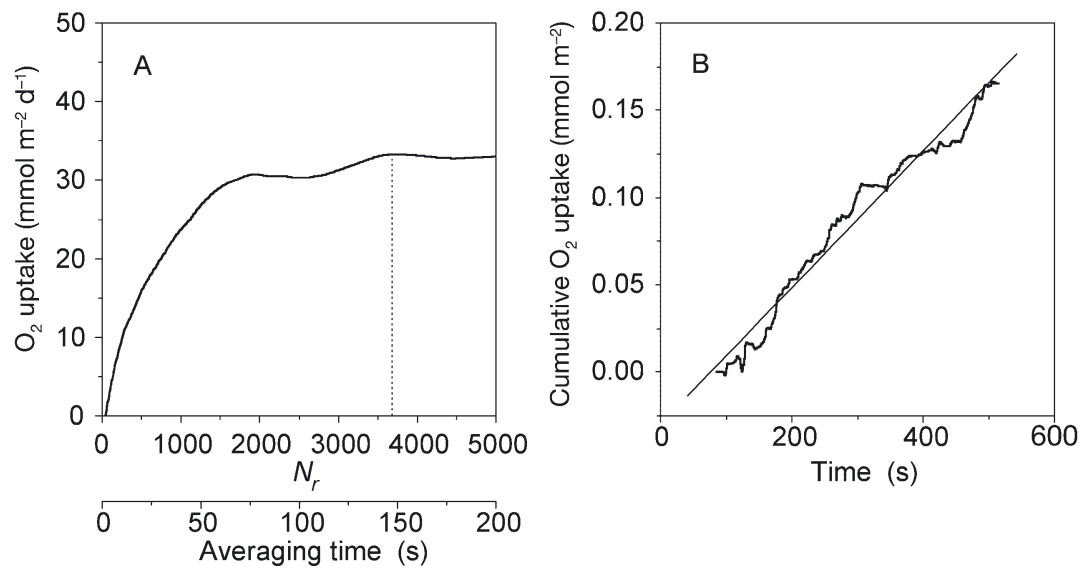

Fig. 7. (A) Determination of number of data points $\left(N_{r}\right)$ used in calculation of running average $\mathrm{O}_{2}$ concentration; dotted line represents chosen $N_{r}$ value of 3700 , corresponding to averaging over $148 \mathrm{~s}$ (lower $x$-axis). (B) Cumulative $\mathrm{O}_{2}$ uptake over time; thin line represents linear fit

relative standard error estimates of $7 \%$ for the chamber measurements and $17 \%$ for the new technique. The latter standard error is considerably larger than for the other sites due to several factors. First, some natural variation in the uptake was expected with the observed changes in current, both in direction and strength. Second, the first and the last data points in the 10 min time series were used only to calculate the running average of $u_{z}$ and were not used directly in the flux calculation. The uptake was for that reason calculated from values of $u_{z}^{\prime}$ and $C$ that only covered a time interval of less than $8 \mathrm{~min}$; this obviously increased the uncertainty of the calculation. A smaller standard error would likely have been found if time series longer than 10 min had been measured at this site.
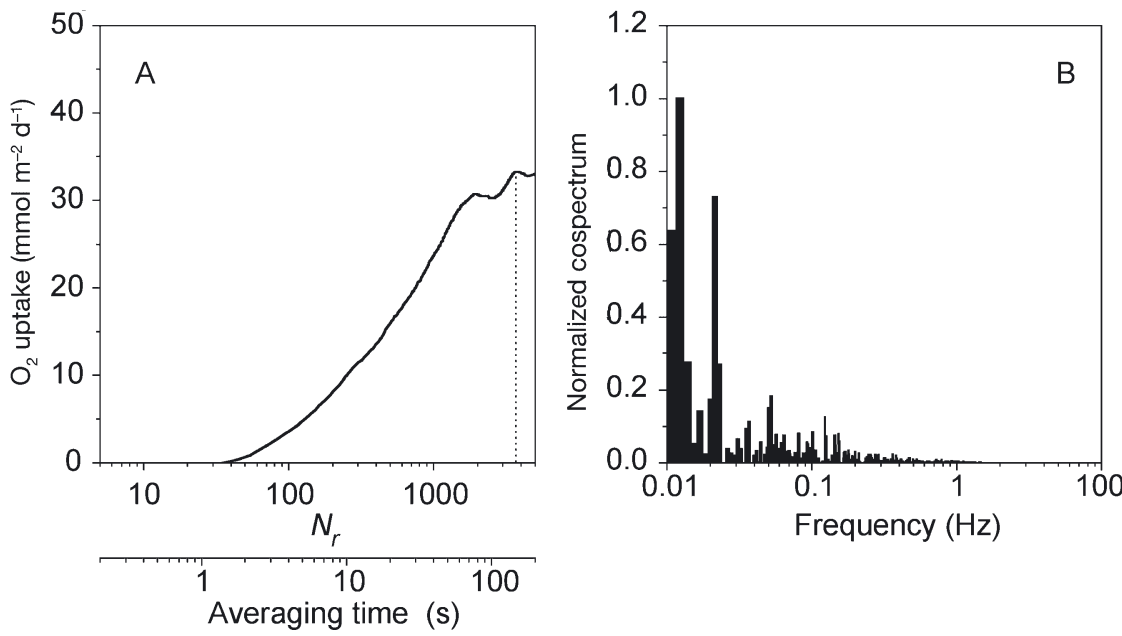

Fig. 8. (A) Data in Fig. 7A on logarithmic x-axis. (B) Normalized 1-sided cospectrum of $u_{z}^{\prime} C^{\prime}$ (see Eq. [1] showing frequencies of turbulent fluctuations responsible for vertical $\mathrm{O}_{2}$ transport)
A further analysis of the eddy-correlation measurements requires that the fluctuating component of the $\mathrm{O}_{2}$ concentration, $C^{\prime}$, is also known. Data from the Aarhus Bay site were used in the example presented below. Since the measured $\mathrm{O}_{2}$ concentration generally contained a slow variation over time, presumably representing a drift in the $\mathrm{O}_{2}$ microelectrode calibration, $C^{\prime}$ must be determined from the running average of $C$. The number of adjacent data points, $N_{r}$, to be included in the running average was found by calculating the $\mathrm{O}_{2}$ uptake repeatedly from Eq. (2) for increasing $N_{r}$ and observing how the uptake changed. An example for one time series is shown in Fig. 7A. Obviously, if $N_{r}=1$, all fluctuations in the time series are filtered out, which means that $C^{\prime}$ equals zero and results in an $\mathrm{O}_{2}$ uptake of zero. For increasing $N_{r}$, an increasing number of turbulent fluctuations are included in the calculation, those with the highest frequency first. The resulting increase in $\mathrm{O}_{2}$ uptake levels off and reaches a near-constant value of $33 \mathrm{mmol} \mathrm{m}^{-2} \mathrm{~d}^{-1}$. It should be noted that the same $\mathrm{O}_{2}$ uptake was calculated for this particular time series by using Eq. (3). The value of $N_{r}$ chosen from these results and used in the further calculations was 3700, corresponding to averaging over $148 \mathrm{~s}$ (Fig. 7A). By knowing both $C^{\prime}$ and $u_{z}^{\prime}$, the cumulative $\mathrm{O}_{2}$ uptake for the time series can be calculated; this exhibited a relatively steady increase through time, as shown in Fig. 7B. The first and the last 1850 data points of a total of 15000 were used only to calculate the running average of $C$, and were not used directly in the flux calculation. This represents a disadvantage of the running average method or other similar averaging methods.

One of our initial concerns in evaluating the new technique was whether the $\mathrm{O}_{2}$ microelectrode would respond fast enough to capture all turbulent fluctuations responsible for the vertical $\mathrm{O}_{2}$ transport toward the sediment. If not, the result would obviously be an underestimation of the $\mathrm{O}_{2}$ uptake. Although the high uptake calculated using the technique suggested that all fluctuations had been accounted for, we investigated this further. From Fig. 8A, which shows the same data as Fig. $7 \mathrm{~A}$ but on a logarithmic $\mathrm{X}$-axis, it is evident that no contributions to $\mathrm{O}_{2}$ up- 
take are calculated for $N_{r}$ smaller than 40 . At the sampling frequency of $25 \mathrm{~Hz}$ used, this value of $N_{r}$ corresponds to averaging over $1.6 \mathrm{~s}$. Thus, it is reasonable to assume that turbulent fluctuations with frequencies higher than $1 \mathrm{~Hz}$, if any, would be included in the calculation at $N_{r}$ equal to 40 . It should be emphasized that all measurements were done using an $\mathrm{O}_{2}$ microelectrode with a $0.2 \mathrm{~s}$ response time for a $90 \%$ response to concentration changes. With this in mind, the results in Fig. 8A indicate that the turbulent transport was facilitated exclusively by fluctuations with frequencies lower than $1 \mathrm{~Hz}$. This result is supported by a calculation of the 1 -sided cospectrum of $u_{z}^{\prime} C^{\prime}$ (Fig. 8B), for the same time series. Although longer time series are required to obtain a smoother variation of the cospectrum, no contributions to the $\mathrm{O}_{2}$ uptake are evident for frequencies higher than $1 \mathrm{~Hz}$. Similar results were obtained in an equivalent analysis of the first series of measurements for the sandy river sediment, where current velocity was more than 6 times greater (data not shown).

The tests of the new technique presented here were conducted under actual field conditions and resulted in successful determination of $\mathrm{O}_{2}$ uptake (Figs. $4,5 \& 6$ ). An analysis of the turbulent fluctuations showed that the response of the $\mathrm{O}_{2}$ microelectrode was sufficiently fast to capture all turbulent eddies contributing to the vertical transport of $\mathrm{O}_{2}$ toward the sediment (Figs. 7 \& 8). Based on these results, we conclude that $\mathrm{O}_{2}$ uptake by aquatic sediments can be determined by the new eddy-correlation technique, and we believe that the technique will become a standard approach for determining $\mathrm{O}_{2}$ uptake by sediments in the future. The technique is superior to conventional methods, as measurements are done under true in situ conditions, i.e. without any disturbance of the sediment and under natural hydrodynamic conditions. In addition, the technique can be used for bio-irrigated or highly permeable sediments, such as sands, where traditional methods often fail. While this paper only focuses on $\mathrm{O}_{2}$ uptake by sediments, the technique can also be applied to other solutes that can be measured at sufficiently high temporal resolution.

We are currently constructing a new device that can position the ADV and the $\mathrm{O}_{2}$ microelectrode at a defined height above the sediment surface, turn these instruments in the horizontal plane, lock them into a position facing the current, and perform measurements, all without support from divers. All electronic equipment will be mounted on the device and we anticipate that sampling can be done under most weather conditions down to a water depth of $200 \mathrm{~m}$. The new device will be used to collect data for various sediments and field conditions, including different current velocities and in the presence of density gradients which have the potential for dampening vertical turbulence. A fu- ture refinement will be to modify the device into a freefalling lander that can descend, land, collect data, and then ascend completely free from any connection to the surface for use at geater depths. We are also currently working on predicting the area of the sediment surface that contributes to the measured $\mathrm{O}_{2}$ uptake. This is done through numerical-mathematical modeling of the 3D transport of $\mathrm{O}_{2}$ in the layer between the sediment surface and the ADV and $\mathrm{O}_{2}$ microelectrode.

Acknowledgements. This study was co-sponsored by the National Science Foundation (OCE-0221259) and the Max Planck Society. The skipper, V. Dam, on the RV 'Genetica II', is thanked for his help during our visits to the marine sites.

\section{LITERATURE CITED}

Aller RC (1983) The importance of the diffusive permeability of animal burrow linings in determining marine sediment chemistry. J Mar Res 41:299-322

Aller RC, Aller JY (1992) Meiofauna and solute transport in marine muds. Limnol Oceanogr 37:1018-1033

Berg P, Rysgaard S, Funch P, Sejr MK (2001) Effects of bioturbation on solutes and solids in marine sediments. Aquat Microb Ecol 26:81-94

Berner RA (1980) Early diagenesis. A theoretical approach. Princeton University Press, Princeton, NJ

Boudreau BP (1997) Diagenetic models and their implementation. Springer-Verlag, Heidelberg

Forster S, Graf G, Kitlar J, Powilleit M (1995) Effects of bioturbation in oxic and hypoxic conditions: a microcosm experiment with a North Sea sediment community. Mar Ecol Prog Ser 116:153-161

Forster S, Huettel M, Ziebis W (1996) Impact of boundary layer flow velocity on oxygen utilization in coastal sediments. Mar Ecol Prog Ser 143:173-185

Fukuchi M, Legendre L, Hoshiai T (1997) The Canada-Japan SARES project on the first-year ice of Saroma-ko Lagoon (northern Hokkaido Japan) and Resolute Passage (Canada High Arctic). J Mar Syst 11:1-8

Glud RN, Holby O, Hoffmann F, Canfield DE (1998) Benthic mineralization and exchange in Arctic sediments (Svalbard, Norway). Mar Ecol Prog Ser 173:237-251

Glud RN, Gundersen JK, Holby O (1999) Benthic in situ respiration in the upwelling area off central Chile. Mar Ecol Prog Ser 186:9-18

Glud RN, Gundersen JK, Røy H, Jørgensen BB (2003) Seasonal dynamics of benthic $\mathrm{O}_{2}$ uptake in a semi enclosed bay: importance of diffusion and fauna activity. Limnol Oceanogr 48:1265-1276

Hayes FR, MacAulay MA (1959) Lake water and sediment. V. Oxygen consumed in water over sediment cores. Limnol Oceanogr 4:291-298

Huettel M, Gust G (1992) Impact of bioroughness on interfacial solute exchange in permeable sediments. Mar Ecol Prog Ser 89:253-267

Huettel M, Webster IT (2001) Porewater flow in permeable sediments. In: Boudreau BP, Jørgensen BB (eds) The benthic boundary layer. Oxford University Press, New York, p 144-179

Jahnke RA, Christiansen MB (1989) A free-vehicle benthic chamber instrument for sea floor studies. Deep-Sea Res 36:625-637 
Lohse L, Epping EHG, Helder W, van Raaphorst W (1996) Oxygen pore water profiles in continental shelf sediments of the North Sea: turbulent versus molecular diffusion. Mar Ecol Prog Ser 145:63-75

Malan DE, McLachlan A (1991) In situ benthic oxygen fluxes in a nearshore coastal marine system: a new approach to quantify the effect of wave action. Mar Ecol Prog Ser 73: 69-81

Mortimer CH (1941) The exchange of dissolved substances between mud and water in lakes. J Ecol 29:280-329

Odum HT (1957) Trophic structure and productivity of Silver Spring, Florida. Ecol Monogr 27:55-112

O'Riordan CA, Maldiney MA, Mouchel JM, Poulin M (1996) A new exploration module for the study of particulate matter transport in rivers. C R Acad Sci Ser II Fasc A Sci Terre Planetes 322(4):285-292

Pamatmat MM, Fenton D (1968) An instrument for measuring subtidal benthic metabolism in situ. Limnol Oceanogr 13: $537-540$

Pelegri SP, Nielsen LP, Blackburn TH (1994) Denitrification in estuarine sediment stimulated by the irrigation activity of the amphipod Corophium volutator. Mar Ecol Prog Ser 105:285-290

Priestley MB (1992) Spectral analysis and time series. Academic Press, London

Rasmussen H, Jørgensen BB (1992) Microelectrode studies of seasonal oxygen uptake in a coastal sediment: role of molecular diffusion. Mar Ecol Prog Ser 81:289-303

Reimers CE, Jahnke RA, Thomsen L (2001) In situ sampling in the benthic boundary layer. In: Boudreau BP, Jørgensen BB (eds) The benthic boundary layer. Oxford University Press, New York, p 245-268

Revsbech NP (1989) An oxygen microelectrode with a guard cathode. Limnol Oceanogr 34:474-478

Reynolds O (1895) On the dynamical theory of incompressible viscous fluids and the determination of the criterion. Phil

Editorial responsibility: Otto Kinne (Editor),

Oldendorf/Luhe, Germany
Trans R Soc Lond A Math Phys Sci 186:123-164

Rutgers van der Loeff MM (1981) Wave effects on sediment water exchange in a submerged sand bed. Neth J Sea Res 15:100-112

Savant SA, Reible DD, Thibodeaux LJ (1987) Convective transport within stable river sediments. Water Resour Res 23:1763-1768

Shirasawa K, Ingram RG, Hudier EJJ (1997) Oceanic heat fluxes under thin sea ice in Saroma-ko Lagoon, Hokkaido Japan. J Mar Syst 11:9-19

Shum KT (1992) Wave-induced advective transport below a rippled water-sediment interface. J Geophys Res 97: 789-808

SonTek/YSI (2001) Acoustic Doppler velocimeter principles of operation. Technical note, September 1, SonTek/YSI, San Diego

Stanišić MM (1985) The mathematical theory of turbulence, Springer-Verlag, New York

Stull RB (1988) An introduction to boundary layer meteorology. Kluwer Academic Publishers, Dordrecht

Thibodeaux LJ, Boyle JD (1987) Bedform-generated convective transport in bottom sediments. Nature 325:341-343

Tietze U, Schenk C (2003) Electronic circuits. Handbook for design and application. Springer-Verlag, Berlin

Wang Y, Van Cappellen P (1996) A multicomponent reactive transport model of early diagenesis: application to redox cycling in coastal marine sediments. Geochim Cosmochim Acta 60:2993-3014

Webster IT (1992) Wave enhancement of solute exchange within empty burrows. Limnol Oceanogr 37:630-643

Webster IT, Taylor JH (1992) Rotational dispersion in porous media due to fluctuating flows. Water Resour Res 28: 109-119

Wyngaard JC (1989) Scalar fluxes in the planetary boundary layer-theory, modeling, and measurement. BoundaryLayer Meteorol 50:49-75

Submitted: March 13, 2003; Accepted: July 24, 2003

Proofs received from author(s): October 7, 2003 